\title{
Henriqueta Lisboa: entre cartas e literatura
}

Kelen Benfenatti Paiva

UFMG / CNPq

\begin{abstract}
RESUMO
O presente artigo pretende apresentar de forma sucinta algumas discussões referentes à correspondência passiva de Henriqueta Lisboa, em especial as cartas de Mário de Andrade, Carlos Drummond de Andrade e Cecília Meireles à poetisa. O objetivo principal é destacar a heterogeneidade do discurso epistolar que ora se apresenta como texto autobiográfico, ora se evidencia como espaço de reflexão sobre questões literárias e sobre a amizade entre intelectuais.

PALAVRAS-CHAVE
\end{abstract}

Epistolografia, Henriqueta Lisboa, Literatura

Ao ler a correspondência passiva de Henriqueta Lisboa, encontramos documentos que relatam histórias de vida, de amizade e de trabalho. São cerca de 3.000 mil documentos entre cartas, cartões, bilhetes e telegramas que recebeu de escritores, artistas, historiadores, críticos, leitores e familiares, além de instituições, editoras e comissões julgadoras de concursos literários. Aproximadamente 729 remetentes assinam a correspondência recebida por ela, dentre os quais lembro: Mário de Andrade, Carlos Drummond de Andrade, Cecília Meireles, Manuel Bandeira, Murilo Rubião, Murilo Mendes, Abgar Renault, Cyro dos Anjos, Alphonsus de Guimaraens Filho, Guimarães Rosa, Jorge Amado, Laís Correia de Araújo, Jorge de Lima, Gabriela Mistral, Jorge Guillén, Roger Bastide, Sérgio Milliet, Antenor Nascente, Antonio Candido, Mário da Silva Brito, Oscar Mendes, entre muitos outros.

Entre os muitos documentos existentes no Acervo de Escritores Mineiros, onde se encontra o espólio deixado pela poetisa, estão seus livros, alguns raros, outros em primeiras edições, títulos autografados, objetos pessoais, fotografias, mobiliário e uma vasta 
correspondência em que se destacam as cartas que recebeu de Mário de Andrade, de Carlos Drummond de Andrade e de Cecília Meireles. Cartas que exemplificam a importância dessa correspondência, pois são preciosas fontes que reúnem informações sobre a autora, sua obra, seus interlocutores e o meio cultural em que viveu.

As cartas e as outras peças do arquivo registram a trajetória literária de Henriqueta Lisboa (1901-1985), sua atuação como professora, poetisa, ensaísta, tradutora e pesquisadora. Na correspondência em destaque é possível apreender algumas questões importantes ao que se refere ao estudo das cartas, que atuam como forma de arquivamento, seja por meio da própria escrita, em que o eu se inscreve e se arquiva, seja por ser mediadora da troca de papéis que alimentam e constituem os arquivos pessoais dos escritores. As cartas que compõem a correspondência de Henriqueta assumem diferentes aspectos: às vezes, assemelham-se a textos autobiográficos, outras vezes, a ensaios ou ainda a testemunhos do processo de criação literária. Nesse sentido, as cartas registram mais que informações sobre vida e obra, relatam o contexto histórico e cultural em que os correspondentes viveram.

\section{CARTAS AUTOBIOGRÁficAS}

Nas cartas estão páginas confessionais que contam histórias de vida e relatam angústias, alegrias e curiosidades da vida dos escritores, como as constantes dores de cabeça e o espírito atordoado de Mário de Andrade; sua decepção e revolta em relação aos "crimes contra a consciência do homem”; seu conflito com o "ser diabólico”, parte integrante de si mesmo. Ou ainda relatos sobre o cotidiano, como os irônicos comentários de Cecília sobre o conflito de interesses com as cozinheiras da casa, a árdua tarefa da administração doméstica em dissonância à função de intelectual e escritora, a luta contra as adversidades da vida e os problemas de saúde que a afligiam.

O aspecto autobiográfico pode ser apreendido nas cartas, na medida em que, ao tratarem de suas histórias, os remetentes se tornam objetos de sua própria escrita. Nas cartas de Cecília Meireles, por exemplo, são comuns as notícias biográficas, os assuntos sobre trabalho, problemas de saúde e viagens, alegrias e tristezas, como se observa na carta de 19 de agosto de 1949:

A vida exige tanto. (...) Minha saúde não é das mais brilhantes neste momento. Primeiro, porque há anos venho lutando com um clima absolutamente adverso e 
uma disciplina de trabalho alucinante - depois, porque também apanhei essa gripe que circula pela cidade e a convalescença não é fácil nem rápida. ${ }^{1}$

As notícias autobiográficas são ainda frequentes no conjunto de cartas enviado a Henriqueta por Mário de Andrade, que se queixa das péssimas condições de saúde, do excesso de trabalho e das dificuldades financeiras, como se pode observar na carta de 12 de setembro de 1943:

\begin{abstract}
Mas palavra, Henriqueta, que tem momentos em que já principio perdendo por completo o controle de mim, fico tão desesperado!... Esta dor que tem mil e um aspectos, mil e uma formas, que não passa mais, está de novo como nos primeiros meses do ano, só que mais cariada e menos vezes com aquela violência que me paralisava morto na cama, às vezes três dias seguidos. Eu creio que agora é pior, é mais martirizante, porque você não imagina o que é, de repente, chegado na noite, dez horas, e você pensa que trabalhou oito, nove horas com dor de cabeça. Vem uma dor ajuntada, dor irrefreável de desespero que cega você. Só prisão de sanatório. ${ }^{2}$
\end{abstract}

As informações biográficas são atrativas ao leitor, por revelarem pessoas de carne e osso e um cotidiano com problemas comuns e muitas vezes parecidos aos dele. De alguma forma essa fragilidade exposta nas cartas cria uma espécie de cumplicidade e satisfação no leitor, que se vê mais próximo da figura do escritor, muitas vezes idealizada por ele mesmo.

As notícias biográficas são menos frequentes nas cartas trocadas entre Drummond e Henriqueta. Diferentemente da atitude de Mário de Andrade e de Cecília Meireles, Drummond se atém poucas vezes a problemas pessoais e mantém o diálogo com a poetisa tratando a maior parte do tempo de poesia. Às vezes, o aspecto autobiográfico da correspondência se evidencia em confissões breves, como em carta de 9 de dezembro de 1952, na qual a poetisa escreve: “Os trabalhos obrigatórios me desgostam de viver em sociedade: chego sempre tarde para as efusões", ${ }^{3}$ ou ainda em momentos em que se percebe alguma característica do correspondente, como nos pedidos de desculpas de Drummond a Henriqueta pela demora da resposta: "Perco-me

${ }^{1}$ CARTA inédita de Cecília Meireles enviada a Henriqueta Lisboa - Acervo de Escritores Mineiros/ UFMG.

${ }^{2}$ CARVALHO. Querida Henriqueta: cartas de Mário de Andrade a Henriqueta Lisboa, p. 131-132.

${ }^{3}$ DUARTE. Remate de males. Correspondência de Carlos Drummond de Andrade e Henriqueta Lisboa, p. 56. 
em pequenas tarefas, e muitas vezes me vejo em falta para com os amigos a quem mais prezo - e este é o caso.”4

\section{CARTAS METALITERÁRIAS}

Cartas metaliterárias também podem ser lidas na correspondência da autora e registram informações sobre os processos criativos dos escritores ou trazem análises de seus textos, como bem se observa nas missivas em que Mário descreve seu duplo processo de criação: a possessão voluntária e a superposição intelectual e declara que guardava seus textos para retornar a eles meses mais tarde em um processo de releitura e reescrita. Em 30 de janeiro de 1942, o autor descreve assim o processo de criação de Paulicéia Desvairada: “foi escrita em puro e total estado de possessão, incrível como vivi, como desvivi, os dias que a escrevi." ${ }^{5}$ Na carta em destaque, Mário realiza uma descrição sistematizada do seu processo criativo:

Si me perguntassem como, quando surge a poesia em mim, eu teria que responder que de qualquer maneira. Só de uma maneira não: jamais decidi que ia escrever uma poesia agora ou depois do jantar (...) já fiz poemas andando na rua, a pé, andando de bonde, de trem, de automóvel (...). A maioria dos meus poemas é “de memória” provocados por experiências já passadas (...). Mas também já fiz muito poema em que o estado-de-poesia se dava durante a experiência (...). Às vezes entre a primeira e a versão definitiva são mais dois poemas irmãos que o mesmo poema. (...) Eu tenho estados poéticos, da maioria dos quais não sou responsável. $^{6}$

Há, nas palavras de Mário, a preocupação em relatar e arquivar informações sobre o nascimento de seus escritos, bem como sobre sua realização poética. Há uma exibição proposital de seu processo criativo que certamente não estaria restrita aos olhos de Henriqueta, mas aos dos futuros leitores de suas “memórias” - sua correspondência.

As cartas de Cecília também são metaliterárias, na medida em que deixam nas entrelinhas pistas sobre seu processo criativo, revelam, por exemplo, sua intrínseca relação com o espaço físico que a cercava e seu fascínio pelas viagens.

Em carta de 9 de julho de 1946, Cecília escreve:

\footnotetext{
${ }^{4}$ DUARTE. Remate de males. Correspondência de Carlos Drummond de Andrade e Henriqueta Lisboa, p. 85.

${ }^{5}$ CARVALHO. Querida Henriqueta: cartas de Mário de Andrade a Henriqueta Lisboa, p. 72.

${ }^{6}$ CARVALHO. Querida Henriqueta: cartas de Mário de Andrade a Henriqueta Lisboa, p. 73.
} 
E nessa bela expectativa, eis que Gabriela me escreve, sugerindo-me ir à Califórnia (...) Não sei se isso será mais que um sonho. E há dois anos que não viajo, e V. não sabe o que é estar parada num lugar a criatura que nasceu para se mover...

As viagens estão presentes em sua obra, seja em uma dimensão geográfica, retratando diferentes cidades europeias, indianas e outras, ou as viagens marítimas portuguesas, seja em uma dimensão metafórica, em que o eu lírico realiza uma infinita viagem de autoconhecimento. Tal presença se evidencia ainda nos depoimentos que concedeu e também nas missivas a Henriqueta, como se observa em uma brincadeira na despedida de uma carta de 14 de novembro de 1944: “Um abraço, Henriqueta e até a próxima carta. Desta sua amiga que gostaria de assinar 'Marco Polo’, mas é apenas a sua, muito carinhosamente, Cecília.” Ou ainda nas confissões da carta de 9 de julho de 1946, em que Cecília fala sobre a escassez de pessoas estimáveis de amizade sem interesses:

Bem, V. já está vendo o que eu penso cá da minha terra, tanto pela necessidade de estar sempre longe dela quanto por essa pescaria de amigos longínquos, que é o meu trabalho sentimental mais primoroso... Daí esse ímpeto permanente, feito de descontínuos ímpetos emendados, para fazer malas, fechar portas, ir por aí afora, na companhia de estrelas e águas.

Viagem parece ter sido para Cecília mais que um tema a ser tratado na poesia, mais que o título do livro de 1939, que a consagrou no cenário das letras nacionais. Sobre isso ela declarou a Pedro Bloch, em entrevista à Revista Manchete: "Viajar para mim nunca foi turismo (...). Viagem é alongamento de horizonte humano." ${ }^{7}$

O aspecto metaliterário de suas cartas é evidenciado mais explicitamente quando a autora narra à amiga de Minas o nascimento de um poema. Em carta de 19 de março de 1945, a autora escreve a Henriqueta sobre o impacto da morte de Mário de Andrade:

Querida Henriqueta: fez-me bem sua cartinha chegada neste momento: sua cartinha fraternal. Desde o princípio deste mês tenho passado bastante mal, com o tremendo abalo da morte de Mário. V. não imagina que choque! Já tenho passado tantos sofrimentos, e ainda não compreendo que havia de tão secretamente íntimo entre nós dois - pois nem nos freqüentávamos muito - para que sua morte fosse como um desabamento por cima de mim. Passei dias e dias sem poder fazer nada com muita clareza, tonta, desgovernada, sentindo tudo que se pode imaginar. (...) Fiquei como sonâmbula, sem achar sentido em nada, viajando também fora da vida.

\footnotetext{
${ }^{7}$ MEIRELES. Pedro Bloch entrevista Cecília Meireles, p. 34-37.
} 
Na mesma carta, narra dois sonhos que teve a respeito da morte do escritor paulista. O primeiro, um dia antes da morte de Mário, em que se viu fechando a porta de um cemitério. O segundo, no sétimo dia de sua morte, em que Mário, já morto, se despedira e caminhara pela praia, e Cecília via-o de costas, meio transparente, seguindo em uma única direção. Fruto do último sonho, teria sido, segundo Cecília, o nascimento de um poema dedicado a Mário:

O morto entrava na minha casa
com a maior naturalidade,
tanta fora a nossa amizade
E esteve entre nós conversando
mas seu olhar estava ausente
de seus olhos, completamente
O morto não tocava o mundo
Lá vinha, sem ser alado,
móvel, desprendido, aéreo, voado.
Apertando-me a mão direita,
disse-me adeus. Sua mão tinha
calor que ainda quando na minha.
E saiu pela praia, fluído,
Como quem de tem rumo certo,
Como quem de tudo está perto,
e o vento em seu vulto batia,
e não há noite nem dia.
Sozinho, o morto caminhava,
tão silencioso, tão secreto
tão de acordo com o próprio vento,
tão puramente pensamento,
tão total e tão despojado,
livre como homem para sempre
que já nem te esqueça nem lembre...

De um sonho, portanto, teria se dado a matéria-prima para a composição do poema dedicado a Mário de Andrade. O relato à amiga revela o trabalho da poetisa com a palavra na construção do poema, que não aparece como fruto de pura inspiração. O evento narrado já estava todo no sonho descrito por Cecília; entretanto, a poetisa lapidou a ideia, transformou as imagens sonhadas em poesia.

\footnotetext{
${ }^{8}$ Poema publicado com o título “O morto” em Poesia completa (2001), com organização de Antonio
} Carlos Secchin. 
Não há, no poema publicado, referência explícita a Mário de Andrade, mas essa informação está na correspondência inédita que manteve com Henriqueta Lisboa. Sobre a morte do autor, Cecília escreve em 27 de abril de 1945, em carta à amiga:

Ah! Henriqueta, triste coisa é a vida! Eu sofro pelo que Mário não pode fazer pelo que nós não poderemos fazer, pelo que ninguém poderá fazer. Ele é uma espécie de símbolo, de centro: é essa precariedade do bom, do belo, do inteligente, do fraternal que me encheu de lágrimas, tanto quanto a perda da pessoa, em si mesma.

Cartas metaliterárias podem ser ainda encontradas na correspondência entre Henriqueta e Drummond, em que os interlocutores abordam a obra literária um do outro criticamente e fazem das cartas espaço privilegiado de reflexão sobre a literatura. Drummond, leitor de Henriqueta, apresenta-se em elogios; Henriqueta, leitora de Drummond, faz das cartas espaço de reflexão e análise literária sobre a poética do autor. Em carta de 2 de setembro de 1942, por exemplo, a poetisa atém-se ao livro Poesias, publicado no mesmo ano, e afirma:

De fato é este o momento psicológico - que tem brilho de aço, lúcido e seco, sob ação do fogo. Talvez amanhã encontremos razões e palavras para contrapor ao seu pessimismo, à crueldade dessa arte, (ó vida futura, nós te criaremos!) mas a sua voz figurará sempre como a voz mais significativa da hora que passa. ${ }^{9}$

Esse exercício de acuidade crítica em relação à obra do poeta é significativo como exemplo do papel da carta como espaço de discussão literária e como evidência de que a literatura foi a principal mediadora do diálogo e a responsável, em parte, pelo nascimento de um sentimento de afetividade e admiração entre os autores, como afirma Drummond em carta de $1^{\circ}$ de março de 1950, na qual agradece o envio do livro Flor da morte e declara: "Seu livro me tornou mais amigo de você."

\section{CARTAS DE AMIZADE}

Os livros de Henriqueta, como atestam as cartas, foram seu principal carisma e motivo de admiração de seus interlocutores. Sobre eles, foram comuns mais que simples elogios, mas assumidos estágios de comunhão, um "encontro com a alma”, nas palavras de Cecília, uma “emoção confraternizadora”, segundo Drummond, ou uma “carícia encantadora”, para Mário.

${ }^{9}$ DUARTE. Remate de males. Correspondência de Carlos Drummond de Andrade e Henriqueta Lisboa, p. 26. 
Pode-se apreender das cartas um verdadeiro tratado de exaltação da amizade, a descrição de um sentimento idealizado, uma "amizade perfeita". ${ }^{10}$ Vários trechos dessa correspondência exemplificam essa celebração de uma "fraternidade espiritual”, como se observa no agradecimento às palavras de Henriqueta sobre um livro seu: "E senti, como da primeira vez, a emoção de uma fraternidade espiritual com uma das criaturas que mais alto coloco na minha estima e na minha admiração." ${ }^{11}$ A poetisa também reitera sua amizade fraternal em várias cartas escritas ao poeta, como na passagem em que se desculpa por não haver escrito a Drummond por seu cinquentenário: "nossa fraternidade é verdadeira e independe, portanto, de qualquer comunicação de data marcada"; ${ }^{12}$ ou ao agradecer-lhe a crônica dedicada à Montanha viva: "Reconheço, com emoção, que raramente se encontra fraternidade igual à sua;"13 ou ainda ao denominá-lo "Irmão maior”, em carta de 4 de fevereiro de 1959, e saudá-lo desta forma no poema “Saudação a Drummond”, escrito pelos 70 anos do poeta:

Eu te saúdo Irmão Maior pelo que tens sido e serás dentro do tempo espaço afora e além da vida: luminar homem simples da terra aprisionado no íntimo para libertador de pássaros e agenciador de símbolos.

Saúdo-te com sete rosas em botão as mais puras colhidas de madrugada antes do sol em suas pétalas por teu sétimo aniversário outrora de menino poeta. ${ }^{14}$

Essa fraternidade espiritual também é apresentada na carta de Cecília, em 16 de janeiro de 1945:

Sabe o que eu acho cada vez mais admirável? A amizade entre gente de letras, principalmente quando essa gente é do nosso sexo. O mundo vai ficando tão horroroso que a amizade vai perdendo o sentido: há aproximações por interesses grosseiros. Pensar que ainda podemos viver a doçura de uma bem-querença puramente espiritual me enche de divina alegria. Mas com um travo de pena pelos que não são capazes disso e desprezam o que desconhecem. ${ }^{15}$

\footnotetext{
${ }^{10}$ Sobre o tema ver ORTEGA. Genealogias da amizade.
} 
Cecília destaca a existência de uma aproximação por interesses grosseiros, um convívio social no mundo das letras que se sustentaria principalmente por benefícios pessoais. A autora parece ressentir-se de tal comportamento e também da ignorância de muitos sobre a existência de uma amizade verdadeira. Nas palavras de Cecília, a amizade é idealizada como um sentimento de “bem-querença puramente espiritual”, sem vínculos a interesses quaisquer, um tipo de amizade perfeita que se daria apenas entre aqueles que estão unidos espiritualmente. Para a autora, a conversa com Henriqueta parece representar um diálogo entre iguais, entre escritoras mulheres que compactuaram dificuldades semelhantes na conquista de um espaço no cenário intelectual de domínio masculino no Brasil durante muitas décadas.

A afinidade espiritual é, repetidas vezes, mencionada por Cecília, que escreve a Henriqueta num tom confessional em que se derramam inquietações sobre a difícil tarefa de ser mulher e escritora, estabelecendo certa cumplicidade feminina. Dessa amizade entre "iguais" nasce a confiança que possibilita desabafos pessoais de Cecília, e comentários ligados ao cotidiano, como a simples dúvida sobre o clima da capital mineira e o tipo de roupa a ser usado em uma conferência. Certamente, esses assuntos, a escritora carioca não trataria com "gente de outro sexo".

A amizade também será celebrada entre Mário de Andrade e Henriqueta, como se observa na carta de 24 de fevereiro de 1940:

(...) sou seu amigo de amizade antiga. Onde já nos conhecemos antes! Não conhecimento de livros, mas daquele conhecimento de desejo, em que, quando se preenche um afeto ainda vago que tínhamos em nós, a pessoa que o preenche é coisa nossa (...). Você é um conhecimento antigo meu, Henriqueta, uma velha amizade que agora apenas veio em realidade preencher o lugar vago que ninguém jamais ocupara. ${ }^{11}$

A declaração de amizade assemelha-se ao amor à primeira vista. Mário celebra a amizade como um sentimento que já existia e que apenas se concretizou com a presença da poetisa. A afetividade se dá a partir do encontro e se mantém pelas muitas cartas trocadas entre eles e, em vez de uma formalidade usual ao se escrever pela primeira vez a alguém, o que vemos na escrita de Mário é informalidade e intimidade justificadas nas próprias palavras do autor pela "amizade antiga.” O afeto de Mário é acolhido pela poetisa que, na carta de 5 de março de 1940, em resposta à primeira carta do modernista, escreve:

\footnotetext{
${ }^{11}$ CARVALHO. Querida Henriqueta: cartas de Mário de Andrade a Henriqueta Lisboa, p. 3.
} 
Com que carinho aguardei, durante quase dois meses, esta carta que há uma semana tenho comigo e que me deixou encantada! Que intensa alegria me causa o afeto com que você se volta para mim! Quantas vezes eu distinguia à distância o seu vulto, imaginando impossível esta aproximação que se realiza de modo estupendamente simples! (...) Adivinhava por certo em você o grande amigo que, depois de deslumbrar-me pela pujança do espírito e pela riqueza do sentimento poético, havia de enternecer-me pela mansuetude do coração. ${ }^{12}$

A amizade celebrada por Mário em relação a Henriqueta Lisboa aparece às vezes mesclada a um sentimento que transita entre o relacionamento fraterno da "irmãzinha de caridade” e a afinidade em relação à mulher, como se mostra nos breves trechos, como no de um bilhete sem data enviado a Henriqueta e guardado com carinho: "Fechei os olhos e quis bem você imensa e comovidamente", ${ }^{13}$ ou a carta de 26 de outubro de 1943: "Não posso mais sem lhe escrever, vivo dia por dia com o meu pensamento todo envolto em carinhos para você.”14 Ou ainda a de 20 de janeiro de 1945: "São 8 horas da manhã, ainda não esquentou o dia, lhe escrevo

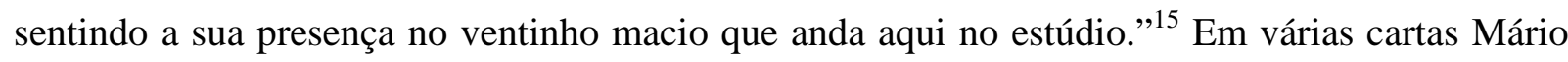
demonstra uma amizade amorosa e derrama-se tanto em carinhos, que permitiu interpretações sobre um possível amor não assumido. E o fato de Henriqueta ter guardado carinhosamente suas cartas em uma caixinha de madeira sobre sua mesa, e uma foto autografada coberta por um pequeno lenço vem reiterar uma quase devoção da poetisa ao escritor, que parece, a muitos, também uma manifestação de amor. A reverência ao retrato assemelha-se à declaração de Mário em carta de 20 de novembro de 1941: "Já coloquei você num dos nichos do altar-mor."” O sentimento que os unia, nomeado como "amizade amorosa”, deve-se às próprias definições do autor que, em carta de 10 de março de 1943, escreveu à poetisa:

Eu sei que nesta comunhão feliz em que nós dois vivemos, nós nos preferiríamos um pouco mais de mãos, não dadas, mas atadas, você se deixando brutalizar pela vida como eu, ou eu me elevando com mais freqüência para as "adivinhas". Nada impede, Henriqueta nada impedirá aquela atração divinatória, aquela escolha muito pouco livre com que nós nos encontramos. E você me perdoou e

\footnotetext{
${ }^{12}$ SOUZA. Correspondência Mário de Andrade \& Henriqueta Lisboa, p. 82.

${ }^{13}$ CARVALHO. Querida Henriqueta: cartas de Mário de Andrade a Henriqueta Lisboa, p. 180.

${ }^{14}$ CARVALHO. Querida Henriqueta: cartas de Mário de Andrade a Henriqueta Lisboa, p. 135.

${ }^{15}$ CARVALHO. Querida Henriqueta: cartas de Mário de Andrade a Henriqueta Lisboa, p. 173.

${ }^{16}$ CARVALHO. Querida Henriqueta: cartas de Mário de Andrade a Henriqueta Lisboa, p. 66.
} 
eu adorei você - e hoje nos amamos com a maior densidade e a maior gratuidade do favor de amigos. ${ }^{17}$

Vale lembrar que essa carta foi escrita três anos após o início da troca de correspondência entre eles, fruto de uma "atração divinatória” concretizada desde o primeiro encontro, e que selou uma “comunhão feliz” e gerou a manifestação de amor.

Os breves excertos da correspondência recebida por Henriqueta de Mário de Andrade, Carlos Drummond de Andrade e de Cecília Meireles evidenciam a heterogeneidade de assuntos e a importância do estudo da correspondência entre escritores como fonte privilegiada de pesquisa. Demonstram, sobretudo, a necessidade cada vez mais iminente de um olhar atento para os arquivos pessoais dos escritores que permitem diversas abordagens sobre nossa história literária.

\begin{abstract}
This paper aims to present some discussion regarding Henriqueta Lisboa's passive correspondence, especially found Mário de Andrade’s, Carlos Drummond de Andrade's and the poet Cecília Meireles's letters. The main objective is to highlight the heterogeneity of epistolary discourse that presents itself as an autobiographical text or as an evidence and as a space for reflection on questions about the literary text and intellectual friendship.
\end{abstract}

Keywords

Henriqueta Lisboa, letter writing, Literature

\title{
REFERÊNCIAS
}

CARVALHO, Abigail Oliveira. Querida Henriqueta: cartas de Mário de Andrade a Henriqueta Lisboa. Rio de Janeiro: José Olympio, 1991.

DUARTE, Constância Lima. Remate de Males. Correspondência de Carlos Drummond de Andrade e Henriqueta Lisboa. Campinas: Departamento de Teoria Literária IEL/UNICAMP, n. 23, 2003.

\footnotetext{
${ }^{17}$ CARVALHO. Querida Henriqueta: cartas de Mário de Andrade a Henriqueta Lisboa, p. 125.
} 
MEIRELES, Cecília. Pedro Bloch entrevista Cecília Meireles. Revista Manchete, Rio de Janeiro, p. 34-37, maio 1964.

MEIRELES, Cecília. Poesia completa. Rio de Janeiro: Nova Fronteira, 2001.

ORTEGA, Francisco. Genealogias da amizade. São Paulo: Iluminuras, 2002.

SOUZA, SOUZA, Eneida Maria de (Org.). Correspondência Mário de Andrade \& Henriqueta Lisboa. São Paulo: Peirópolis/Edusp, 2010. 